ARTICLE

Received 21 Oct 2014 | Accepted 5 Jan 2015 | Published 5 Feb 2015

DOI: $10.1038 /$ ncomms 7207

OPEN

\title{
Carbon-carbon bond activation of cyclobutenones enabled by the addition of chiral organocatalyst to ketone
}

Bao-Sheng Li ${ }^{1}$, Yuhuang Wang ${ }^{1}$, Zhichao Jin ${ }^{1}$, Pengcheng Zheng ${ }^{2}$, Rakesh Ganguly ${ }^{1} \&$ Yonggui Robin Chi ${ }^{1,2}$

The activation of carbon-carbon (C-C) bonds is an effective strategy in building functional molecules. The $\mathrm{C}-\mathrm{C}$ bond activation is typically accomplished via metal catalysis, with which high levels of enantioselectivity are difficult to achieve due to high reactivity of metal catalysts and the metal-bound intermediates. It remains largely unexplored to use organocatalysis for $\mathrm{C}-\mathrm{C}$ bond activation. Here we describe an organocatalytic activation of $\mathrm{C}-\mathrm{C}$ bonds through the addition of an $\mathrm{NHC}$ to a ketone moiety that initiates a $\mathrm{C}-\mathrm{C}$ single bond cleavage as a key step to generate an NHC-bound intermediate for chemo- and stereo-selective reactions. This reaction constitutes an asymmetric functionalization of cyclobutenones using organocatalysts via a C-C bond activation process. Structurally diverse and multicyclic compounds could be obtained with high optical purities via an atom and redox economic process.

\footnotetext{
${ }^{1}$ Nanyang Technological University, Division of Chemistry \& Biological Chemistry, School of Physical \& Mathematical Sciences, Singapore, 637371, Singapore.

${ }^{2}$ Laboratory Breeding Base of Green Pesticide and Agricultural Bioengineering, Key Laboratory of Green Pesticide and Agricultural Bioengineering, Ministry of Education, Guizhou University, Huaxi District, Guiyang 550025, China. Correspondence and requests for materials should be addressed to Y.R.C.

(email: robinchi@ntu.edu.sg).
} 
T he catalytic activation of a carbon-carbon $(\mathrm{C}-\mathrm{C})$ single bond of cyclobutenones can provide direct methods towards building useful molecules ${ }^{1-5}$. Despite the rather clear practical significance, $\mathrm{C}-\mathrm{C}$ bond activation remains challenging. Traditionally, this process is initiated by the oxidative addition of a transition metal catalyst to the $\mathrm{C}-\mathrm{C}$ bond followed by other bond breaking and formation events (Fig. 1a). Due to the high reactivities of the metal catalyst and the metal-bound intermediates, chemoselectivity is generally difficult to control. In addition, it still remains difficult to achieve high levels of enantioselectivity using the transition metal-catalysed $\mathrm{C}-\mathrm{C}$ bond activation approach ${ }^{6-1}$. In many cases, intramolecular reactions were used to overcome the challenging selectivity issues.

Our laboratory is interested in developing organocatalysis for challenging bond activations while maintaining the power of organocatalysis for chemo- and stereo-selectivity control. Herein, we report the addition of an $\mathrm{N}$-heterocyclic carbene (NHC) organocatalyst to a ketone moiety that initiates a $\mathrm{C}-\mathrm{C}$ single bond cleavage to generate an NHC-bound intermediate for chemo- and stereo-selective reactions (Fig. 1b). Compared with the earlier NHC catalysis (such as oxidative NHC catalysis for $\gamma$-carbon functionalization of enals $)^{12-18}$, in this approach all atoms of the substrate end up in the product (atom economy) and the overall reaction is redox-neutral (redox economy) $)^{19}$. Specifically, the addition of an NHC catalyst to an unsaturated four-membered cyclo-ketone substrate to form intermediate I. Breaking a C-C bond of the four-membered ring eventually generates a vinyl enolate intermediate ${ }^{12-22}$ II that reacts with an imine substrate to form the lactam product. NHC catalysis is routinely used in the activation of aldehydes through the formation of Breslow intermediates ${ }^{23-32}$. The addition of NHC catalyst to ketone moiety for reactions is much less studied, except for the activation of $\alpha$-hydroxyl ketones via retro-benzoin pathways as nicely illustrated by Bode and co-workers ${ }^{33,34}$.

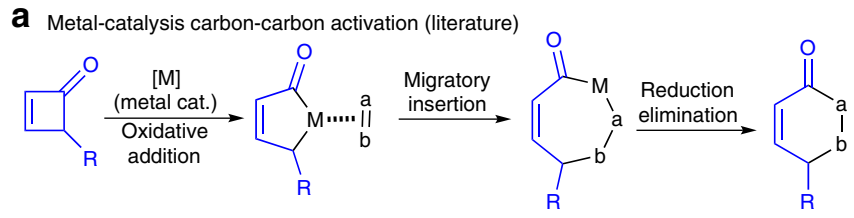

(typical approach for metal-catalyzed activation C-C bond)

b Organocatalytic carbene C-C bond activation (this work)

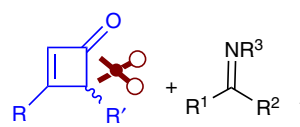

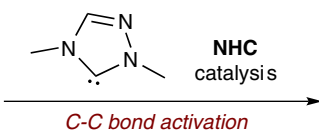

( \pm ) 1 2

$$
\text { - Atom economy }
$$
- Redox economy<smiles>[3H]C#N</smiles><smiles></smiles><smiles></smiles>
$\underset{\text { formal }[4+2]}{\stackrel{2}{\longrightarrow}}$<smiles>[R7][R]1NC(=O)C=C([R])[C]1[R]</smiles>

\section{Results}

Reaction optimization. As briefed in Table 1, triazolium NHCs (A, B, entries 1 and 2) could smoothly mediate the formation of desired product $3 \mathbf{a}$ as essentially a single diastereomer. The $\mathrm{N}$-aryl substituent (phenyl or mesityl) of pre-catalyst $\mathbf{A}^{48}$ and $\mathbf{B}^{49,50}$ had little effect on the reaction yield. Next the enantioselectivity of this transformation was evaluated with aminoindanol-derived triazolium salts $\mathbf{C}-\mathbf{F}^{49-52}$ (entries 3-6). In all cases, the product 3a was formed essentially as a single diastereomer with good yields (entries 1-6). Among precatalysts $\mathbf{C}-\mathbf{F}$, the $\mathrm{N}$-aryl substituents could affect the reaction enantioselectivities (entries $3-6)$. The use of $N$-mesityl substituted triazolium catalyst $\mathbf{D}^{48}$ gave the product 3a with the highest enantioselectivity (90:10 er) and good yield (84\%, entry 4$)$. We then noticed that increasing the reaction temperature to $55^{\circ} \mathrm{C}$ could reduce the reaction time from 48 to $24 \mathrm{~h}$ and there was a small but reproducible increase of

Table 1 | Condition optimization.

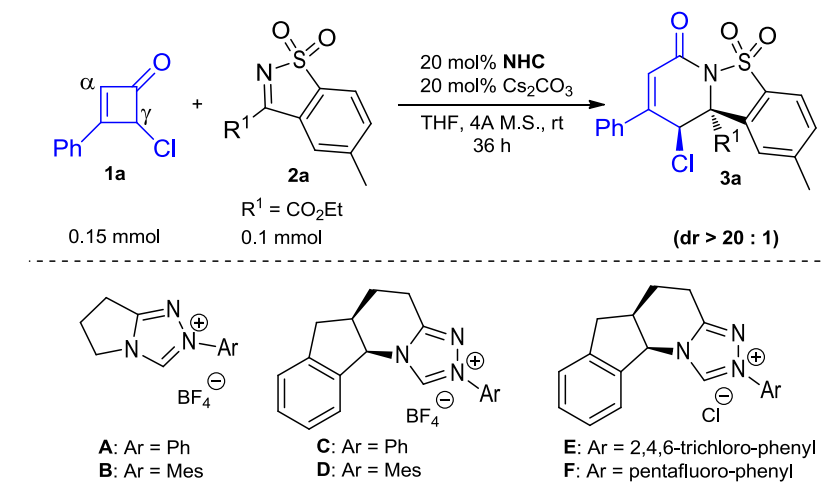

\begin{tabular}{|c|c|c|c|}
\hline Entry & NHC & $3 a$ yield $(\%)^{\dagger}$ & $3 a$ er $(\%)^{\ddagger}$ \\
\hline 1 & A & 71 & - \\
\hline 2 & B & 75 & - \\
\hline 3 & C & 81 & 83:17 \\
\hline 4 & D & 84 & $90: 10$ \\
\hline 5 & E & 83 & $64: 36$ \\
\hline 6 & $\mathbf{F}$ & 55 & $75: 25$ \\
\hline 7 & D, $55^{\circ} \mathrm{C}, 24 \mathrm{~h}$ & 83 & $92: 8$ \\
\hline \multicolumn{4}{|c|}{ 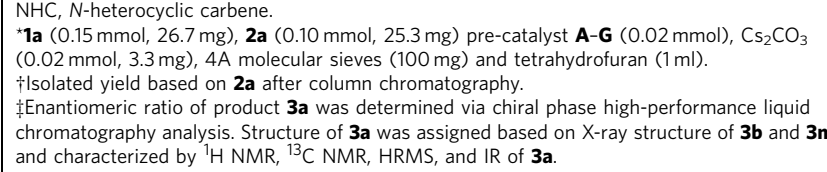 } \\
\hline
\end{tabular}


er without sacrificing the yield or er (entry 7) for unclear reasons. Interestingly, there was a small but reproducible increase of er when increasing the reaction temperature from room temperature (90:10 er, entry 4$)$ to $55^{\circ} \mathrm{C}(92: 8 \mathrm{er}$, entry 7$)$.

Substrates scope with sulfonyl imines. With optimized condition (Table 1, entry 7) in hand, we next evaluated the scope of this reaction (Fig. 2). The $\mathrm{R}^{\prime}$ substituent at the $\gamma$-carbon of cyclobutenone 1 could be $\mathrm{Cl}(\mathbf{3 a})$, methyl (3b) or a proton (3c). When the R' substituent was an aryl unit, the $\alpha, \beta$-double bond in the fourmembered ring could easily migrate to the $\beta, \gamma$-carbons. Placing a substituent (such as a $\mathrm{CH}_{3}$ or $\mathrm{Cl}$ unit) at the $\alpha$-carbon of $\mathbf{1}$ led to nearly no reaction, and the ketone substrate was recovered under the reaction condition. The $\beta$-aryl group of $\mathbf{1}$ could be replaced with an alkenyl (3d), cyclohexyl (3e) or a tert-butyl (3f)

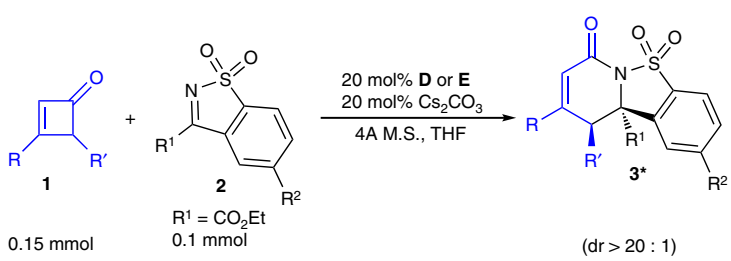

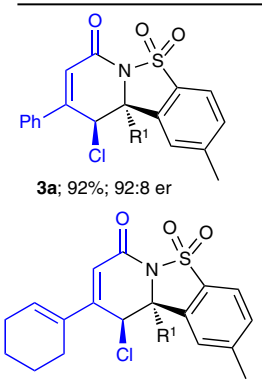

3d; $82 \%$; $91: 9$ er<smiles>[R]C1=CC(=O)N2[C@@H](c3cc(C)ccc3S2(=O)=O)[C@H](Cl)C1[R]</smiles>
$\begin{aligned} \mathrm{R}= & 4-\mathrm{CH}_{3}-\mathrm{C}_{6} \mathrm{H}_{5} ; \mathbf{3 g} ; 90 \% ; 91: 9 \mathrm{er} \\ & 4-{ }^{-} \mathrm{Bu}-\mathrm{C}_{6} \mathrm{H}_{5} ; \mathbf{3 h} ; 65 \% ; 95: 5 \mathrm{er} \\ & 4-\mathrm{OMe}^{-} \mathrm{C}_{6} \mathrm{H}_{5} ; \mathbf{3 i} ; 76 \% ; 96: 4 \mathrm{er} \\ & 3-\mathrm{CH}_{3}-\mathrm{C}_{6} \mathrm{H}_{5} ; \mathbf{3 j} ; \mathbf{7 8 \%} ; 93: 7 \mathrm{er}\end{aligned}$<smiles>O=C1C=C(C2CCCCC2)C(Cl)[C@H]2c3cc(Cl)ccc3S(=O)(=O)N12</smiles><smiles>O=C1C=C(C2=CCCCC2)[C@H](Cl)[C@H]2c3cc(Cl)ccc3S(=O)(=O)N12</smiles>

3q; $86 \% ; 77: 23 \mathrm{er}^{\star \star \star}$ (n.r.) ${ }^{\star \star}$

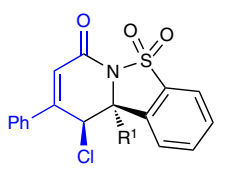

3r; 82\%; 83:17 er ${ }^{\star \star}$

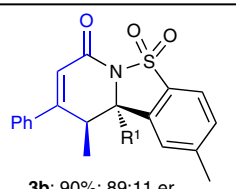

3b; $90 \%$; 89:11 er

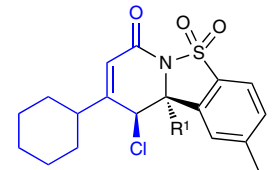

3e; $84 \%$; $96: 4$ er
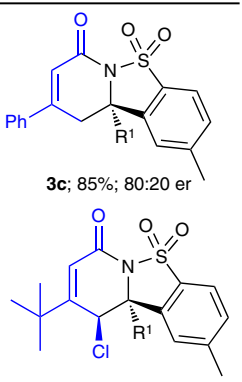

3f; $76 \% ; 94: 6$ er
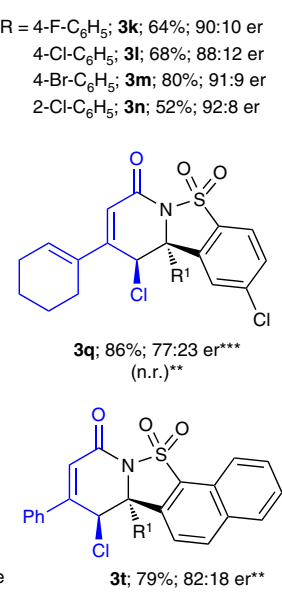

Figure $\mathbf{2}$ | Reaction scope. ${ }^{*}$ The scope of this catalytic transformation was evaluated under standard conditions (Table 1, entry 7). Substrate scope includes $\gamma$ - (3a-3c) and $\beta$-substituents (3d-3n) cyclobutenones (using $\mathbf{2 a}$ as the optimal imine), and various imines (3o-3t, using $\mathbf{1 a}$ as the optimal substrate). Reported yields were isolated yields of $\mathbf{3}$ based on imine $\mathbf{2}$. Diastereoselective ratio ( $\mathrm{dr}$ of $\mathbf{3}$ was determined via ${ }^{1} \mathrm{H}$ NMR analysis of the unpurified reaction mixture. Relative configuration of the major diastereoisomer was assigned based on X-ray structure of $\mathbf{3 b}$ and $\mathbf{3 m}$ (CCDC 988901, CCDC 988902, see Supplementary Information for more details). ${ }^{\star *}$ The reactions were performed at $25^{\circ} \mathrm{C}$ for $36 \mathrm{~h}$. ${ }^{\star \star \star}$ The reactions were performed using pre-catalyst $\mathbf{E}$ at $25^{\circ} \mathrm{C}$ for $36 \mathrm{~h}$ (the reaction temperature was $0^{\circ} \mathrm{C}$ for $\mathbf{3 p}$ ). substituent. Placing substituents with various electronic properties at the $\beta$-aryl group of $\mathbf{1}$ were all tolerated $(\mathbf{3 g}-\mathbf{n})$. When an electron withdrawing group $(\mathrm{Cl})$ was used to replace the methyl group of imine substrate $\mathbf{2}(\mathbf{3 o}-\mathbf{3 q})$, the reaction gave good yields but much lower ers. We then found that by using the more electron-deficient NHC pre-catalyst $\mathbf{E}$, the products $(\mathbf{3 o}-\mathbf{3 q})$ could be obtained with good to excellent enantiomeric excesses. It appears that the electronic properties of both the imine substrates and NHC catalysts could significantly affect the enantioselectivities in our reaction system ${ }^{53-56}$. For example, with the $N$ mesityl catalyst $\mathbf{D}$ as the NHC pre-catalyst, the reaction with imine 2a gave product 3a with 92:8 er; while under the same conditions the use of imine substrate with a chlorine substituent gave product 3o with $65: 35 \mathrm{er}$. Similar effects with $N$-trichloro phenyl catalyst $\mathbf{E}$ were observed. When $\mathbf{E}$ was the catalyst, $\mathbf{3 a}$ was obtained with 64:36 er (Table 1, entry 5) while $\mathbf{3 o}$ was observed with 95:5 er. The imine substrate bearing no substituent at the phenyl group also reacted well to give $\mathbf{3 r}$ with good yield, albeit with lower er. Results comparable to those of $\mathbf{3 r}$ were observed when imines bearing a methoxylphenyl (3s) or naphthyl (3t) unit were used.

Substrates scope with isatin imines. To further explore the scope of the $\mathrm{C}-\mathrm{C}$ bond activation reaction, we next examined Bocprotected imines derived from isatins to react with cyclobutenones 1 (Fig. 3). Catalyst $\mathbf{D}$ used in the earlier reactions (Table 1) was found effective here. Optimal results were obtained when the reactions were performed at room temperature for $72 \mathrm{~h}$. The reactions proceeded to give tricyclic molecules $(\mathbf{5 a}-\mathbf{g})$ containing spiro quaternary carbon centres with good drs and excellent ers. When substrate with electron-donating substituent (such as a methoxyl group, $\mathbf{5 h}$ ) was used, a drop in both the reaction yields and stereo-selectivities were observed.

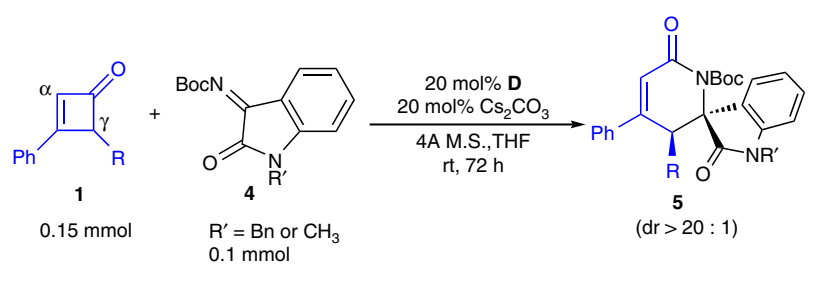<smiles>O=C1C=C(c2ccccc2)[C@@H](Cl)[C@](C(=O)Nc2ccccc2)(c2ccccc2)[15NH]1</smiles>

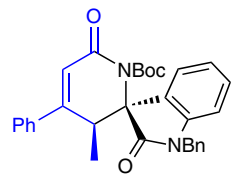

5b; $71 \% ; 7: 1 \mathrm{dr}:>99: 1$ er

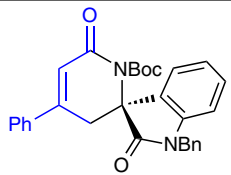

5c; $81 \% ; 93: 7$ er<smiles>CNC(=O)c1ccccc1[C@]1(C(=O)NC)NC(=O)C=C(c2ccccc2)[C@H]1Cl</smiles>

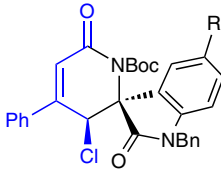

$\mathrm{R}^{1}=\mathrm{F} ; \mathbf{5 e} ; 83 \% ; 20: 1 \mathrm{dr} ; 99: 1 \mathrm{er}$ $\mathrm{Cl} ; \mathbf{5 f} ; 73 \% ; 7: 1 ; \mathrm{dr} ; 95: 5$ er $\mathrm{Br} ; \mathbf{5 g} ; 77 \% ; 17: 1 \mathrm{dr} ; 98: 2 \mathrm{er}$ $\mathrm{CH}_{3} \mathrm{O}, \mathbf{5 h}, 40 \% ; 3: 1 \mathrm{dr}, 70: 30$ er

Figure 3 | Reaction scope. Substrate scope includes $\beta$-phenyl with various $\gamma$-substituents (1a-1c; using $\mathbf{4 a}$ as the optimal imine), and various imines (using $\mathbf{1 a}$ as the optimal substrate). Reported yields were isolated yields of $\mathbf{5}$ based on imine $\mathbf{4}$. Diastereoselective ratio ( $d r$ of $\mathbf{5}$ was determined via ${ }^{1} \mathrm{H}$ NMR analysis of the unpurified reaction mixture. Relative configuration of the major diastereoisomer was assigned based on X-ray structure of $\mathbf{5 f}$ and $\mathbf{5 g}$ (CCDC 1011138 and CCDC 1011137, see Supplementary Information for more details). Ers (major diastereomer) were determined via chiral phase high-performance liquid chromatography analysis. 


\section{Discussion}

These two types of reactions summarized in Figs 2 and 3 exemplified the potential value of our $\mathrm{C}-\mathrm{C}$ activation strategy. The resulting products contains two contiguous stereogenic centres and one aza-quaternary center. Notably, our approach also allows for the construction of chiral carbon stereocenters bearing a $\mathrm{Cl}$ atom. The absolute configurations of the reaction products were determined based on their ${ }^{1} \mathrm{H}$ nuclear magnetic resonance $\left({ }^{1} \mathrm{H}\right.$ NMR) spectra and X-ray diffraction of the products $\mathbf{3 b}, \mathbf{3 m}, \mathbf{5} \mathbf{f}$ and $\mathbf{5 g}$.

As a note, installing substituents at the ketone $\beta$-aryl group led to a significant drop in the reaction yields with little or no enantioselectivities for the isatin imine reactions, for reasons unclear at this moment (Fig. 3). The use of other imines (such as $N$-tosyl imine derived from benzaldehyde or aryl trifluoroacetone) led to no detecable lactam product. The imine substrates were hydrolysed at an elongated time in our reaction system. A better understanding between the substrate structures and reactivities require further investigations.

In addition, cyclobutenones are known to undergo ring opening to form vinyl ketenes under thermal conditions. However, in our reactions such ring opening was unlikely to occur because: (a) the cyclobutenone substrates were stable (no ring opening) in the absence of carbene catalysts under our reaction condition, (b) our catalytic condition could occur at room or lower temperatures, such as synthesis of the product $\mathbf{3 p}$ in Fig. 2. In our reaction, the addition of carbene catalyst initiated a key $\mathrm{C}-\mathrm{C}$ breaking step to generate the vinyl enolate intermediate ${ }^{57}$.

In summary, we have demonstrated the use of an NHC catalyst to catalyse the breaking of $\mathrm{C}-\mathrm{C}$ single bonds for asymmetric reactions ${ }^{58-67}$. To the best of our knowledge, this is the first example demonstrating asymmetric functionalization of cyclobutenone using organocatalyst. Structurally diverse and multicyclic compounds could be obtained with high optical purities via an atom and redox economical process. Built upon this strained four-membered ring ketone activation, we are looking into other more common ketone compounds. We also expect this study to encourage further investigations into organocatalytic strategies for new $\mathrm{C}-\mathrm{C}$ activations and highly economical syntheses.

\section{Methods}

Materials. For ${ }^{1} \mathrm{H},{ }^{13} \mathrm{C}$ NMR and high-performance liquid chromatography spectra of compounds in this manuscript, see Supplementary Figs 1-68. For details of the synthetic procedures, see Supplementary Methods.

Syntheses of products $\mathbf{3}$ and 5. To a dry Schlenk tube equipped with a magnetic stir bar, were added cyclobuteneones $1(0.15 \mathrm{mmol})$, imines 2 or $4(0.1 \mathrm{mmol})$, triazolium salt $\mathbf{D}$ or $\mathbf{E}(0.02 \mathrm{mmol}), \mathrm{Cs}_{2} \mathrm{CO}_{3}(0.02 \mathrm{mmol}, 6.5 \mathrm{mg})$ and $4 \mathrm{~A}$ molecular sieve $(100 \mathrm{mg})$. The tube was closed with a septum, evacuated and refilled with nitrogen. Then, the freshly distilled tetrahydrofuran $(1.0 \mathrm{ml})$ was added. The reaction mixture was stirred at the specified temperature as showed in Fig. 2 and Fig. 3 in the text. After the complete consumption of imines by was monitoring by thin-layer chromatography, the mixture was concentrated under reduced pressure. The resulting crude residue was purified via column chromatography on silica gel to afford the desired products $\mathbf{3}$ or $\mathbf{5}$.

\section{References}

1. Crabtree, R. H. The organometallic chemistry of alkanes. Chem. Rev. 85, 245 (1985).

2. Rybtchinski, B. \& Milstein, D. Metal insertion into C-C bonds in solution. Angew. Chem. Int. Ed. 38, 870 (1999).

3. Jun, C.-H. Transition metal-catalyzed carbon-carbon bond activation. Chem. Soc. Rev. 33, 610 (2004).

4. Nečas, D. \& Kotora, M. Rhodium-catalyzed C-C bond cleavage reactions. Curr. Org. Chem. 11, 1566 (2007).

5. Seiser, T., Saget, T., Tran, D. N. \& Cramer, N. Cyclobutanes in catalysis. Angew. Chem. Int. Ed. 50, 7740 (2011).
6. Matsuda, T., Shigeno, M. \& Murakami, M. Asymmetric synthesis of 3,4-dihydrocoumarins by rhodium-catalyzed reaction of 3-(2-hydroxyphenyl) cyclobutanones. J. Am. Chem. Soc. 129, 12086 (2007).

7. Nájera, C. \& Sansano, J. M. Asymmetric intramolecular carbocyanation of alkenes by C-C bond activation. Angew. Chem. Int. Ed. 48, 2452 (2009).

8. Winter, C. \& Krause, N. Rhodium(I)-catalyzed enantioselective C-C bond activation. Angew. Chem. Int. Ed. 48, 2460 (2009).

9. Seiser, T. \& Cramer, N. Enantioselective metal-catalyzed activation of strained rings. Org. Biomol. Chem. 7, 2835 (2009).

10. Xu, T., Ko, H. M., Savage, N. A. \& Dong, G. Highly enantioselective Rhcatalyzed carboacylation of olefins: efficient syntheses of chiral poly-fused rings. J. Am. Chem. Soc. 134, 20005 (2012).

11. Souillart, L., Parker, E. \& Cramer, N. Highly enantioselective rhodium(i)catalyzed activation of enantiotopic cyclobutanone c-c bonds. Angew. Chem. Int. Ed. 53, 3001 (2014).

12. Mo, J., Chen, X. \& Chi, Y. R. Oxidative $\gamma$-addition of enals to trifluoromethyl ketones: enantioselectivity control via Lewis acid/ $N$-heterocyclic carbene cooperative catalysis. J. Am. Chem. Soc. 134, 8810 (2012).

13. Chen, X., Yang, S., Song, B. A. \& Chi, Y. R. Functionalization of benzylic $\mathrm{C}\left(\mathrm{sp}^{3}\right)-\mathrm{H}$ bonds of heteroaryl aldehydes through $\mathrm{N}$-heterocyclic carbene organocatalysis. Angew. Chem. Int. Ed. 52, 11134 (2013).

14. Chen, X.-Y., Xia, F., Cheng, J.-T. \& Ye, S. Highly enantioselective g-amination by $N$-heterocyclic carbene catalyzed $[4+2]$ annulation of oxidized enals and azodicarboxylates. Angew. Chem. Int. Ed. 52, 10644 (2013).

15. Maki, B. E., Chan, A., Phillips, E. M. \& Scheidt, K. A. Tandem oxidation of allylic and benzylic alcohols to esters catalyzed by $N$-heterocyclic carbenes. Org. Lett. 9, 371 (2007).

16. Guin, J., De Sarkar, S., Grimme, S. \& Studer, A. Biomimetic carbenecatalyzed oxidations of aldehydes using TEMPO. Angew. Chem. Int. Ed. 47, 8727 (2008).

17. De Sarkar, S., Grimme, S. \& Studer, A. NHC catalyzed oxidations of aldehydes to esters: chemoselective acylation of alcohols in presence of amines. J. Am. Chem. Soc. 132, 1190 (2010).

18. Chiang, P.-C. \& Bode, J. W. On the role of $\mathrm{CO}_{2}$ in NHC-catalyzed oxidation of aldehydes. Org. Lett. 13, 2422 (2011).

19. Jian, T.-Y., Shao, P.-L. \& Ye, S. Enantioselective [4+2] cycloaddition of ketenes and 1 -azadienes catalyzed by $N$-heterocyclic carbenes. Chem. Commun. 47, 2381 (2011).

20. Tiseni, P. S. \& Peters, R. Catalytic asymmetric formation of $\delta$-lactones by $[4+2]$ cycloaddition of zwitterionic dienolates generated from $\alpha, \beta$-unsaturated acid chlorides. Angew. Chem. Int. Ed. 46, 5325 (2007).

21. Tiseni, P. S. \& Peters, R. Lewis acid - Lewis base catalyzed enantioselective Hetero-Diels - Alder reaction for direct access to $\delta$-lactones. Org. Lett. 10, 2019 (2008).

22. Shen, L., Sun, L. \& Ye, S. Highly enantioselective $\gamma$-amination of $\alpha, \beta$ unsaturated acyl chlorides with azodicarboxylates: efficient synthesis of chiral $\gamma$-amino acid derivatives. J. Am. Chem. Soc. 133, 15894 (2011).

23. Breslow, R. On the mechanism of thiamine action. $1 \mathrm{~V}^{1}$ evidence from studies on model system. J. Am. Chem. Soc. 80, 3719 (1958).

24. Enders, D. \& Kallfass, U. An efficient nucleophilic carbene catalyst for the asymmetric benzoin condensation. Angew. Chem. Int. Ed. 41, 1743 (2002).

25. Burstein, C. \& Glorius, F. Organocatalyzed conjugate Umpolung of $\alpha, \beta$ unsaturated aldehydes for the synthesis of $\gamma$-butyrolactones. Angew. Chem. Int. Ed. 43, 6205 (2004).

26. Takikawa, H., Hachisu, Y., Bode, J. W. \& Suzuki, K. Catalytic enantioselective crossed aldehyde-ketone benzoin cyclization. Angew. Chem. Int. Ed. 45, 3492 (2006).

27. Nair, V., Vellalath, S., Poonoth, M. \& Suresh, E. N-heterocyclic carbenecatalyzed reaction of chalcones and enals via homoenolate: an efficient synthesis of 1,3,4-trisubstituted cyclopentenes. J. Am. Chem. Soc. 128, 8736 (2006).

28. Phillips, E. M., Wadamoto, M., Chan, A. \& Scheidt, K. A. A highly enantioselective intramolecular Michael reaction catalyzed by $N$-heterocyclic carbenes. Angew. Chem. Int. Ed. 46, 3107 (2007).

29. Liu, Q., Perreault, S. \& Rovis, T. Catalytic asymmetric intermolecular stetter reaction of glyoxamides with alkylidenemalonates. J. Am. Chem. Soc. 130, 14066 (2008).

30. Du, D. \& Wang, Z. N-heterocyclic carbene catalyzed domino reactions of formylcyclopropane 1,1-diesters: a new synthesis of coumarins. Eur. J. Org. Chem. 4949 (2008).

31. Du, D., Li, L. \& Wang, Z. N-heterocyclic carbene-catalyzed domino ringopening/redox amidation/cyclization reactions of formylcyclopropane 1,1diesters: direct construction of a 6-5-6 tricyclic hydropyrido[1,2-a]indole skeleton. J. Org. Chem. 74, 4379 (2009).

32. Lv, H., Mo, J., Fang, X. \& Chi, Y. R. Formal Diels-Alder reactions of chalcones and formylcyclopropanes catalyzed by chiral $\mathrm{N}$-heterocyclic carbenes. Org. Lett. 13, 5366 (2011). 
33. Chiang, P.-C., Rommel, M. \& Bode, J. W. $\alpha^{\prime}$-hydroxyenones as mechanistic probes and scope-expanding surrogates for $\alpha, \beta$-unsaturated aldehydes in $N$-heterocyclic carbene-catalyzed reactions. J. Am. Chem. Soc. 131, 8714 (2009).

34. Binanzer, M., Hsieh, S.-Y. \& Bode, J. W. Catalytic kinetic resolution of cyclic secondary amines. J. Am. Chem. Soc. 133, 19698 (2011).

35. Lesma, G., Landoni, N., Sacchetti, A. \& Silvani, A. The Spiroperidine-3-3'oxindole scaffold: a type II $\beta$-turn peptide isostere. Tetrahedron 66, 4474 (2010).

36. Murakami, M., Amii, H., Shigeto, K. \& Ito, Y. Breaking of the C-C bond of cyclobutanones by rhodium(I) and its extension to catalytic synthetic reactions. J. Am. Chem. Soc. 118, 8285 (1996).

37. Murakami, M., Ashida, S. \& Matsuda, T. Eight-membered ring construction by $[4+2+2]$ annulation involving $\beta$-carbon elimination. J. Am. Chem. Soc. 128, 2166 (2006).

38. Cammers-Goodwi, A. Tri-n-butylphosphine-catalyzed addition and ring-cleavage reactions of cyclobutenones. J. Org. Chem. 58, 7619 (1993).

39. Murakami, M., Miyamoto, Y. \& Ito, Y. Dimeric triarylbismuthane oxide: a novel efficient oxidant for the conversion of alcohols to carbonyl compounds. J. Am. Chem. Soc. 123, 6441 (2001).

40. Magomedov, N. A., Ruggiero, P. L. \& Tang, Y. Remarkably facile hexatriene electrocyclizations as a route to functionalized cyclohexenones via ring expansion of cyclobutenones. J. Am. Chem. Soc. 126, 1624 (2004).

41. Xu, T. \& Dong, G. Rhodium-catalyzed regioselective carboacylation of olefins: A C-C bond activation approach for accessing fused-ring systems. Angew. Chem. Int. Ed. 51, 7567 (2012).

42. Ko, H. M. \& Dong, G. Cooperative activation of cyclobutanones and olefins leads to bridged ring systems by a catalytic [4+2] coupling. Nat. Chem. 6, 789 (2014).

43. Nishimura, T. \& Uemura, S. Palladium-catalyzed arylation of tert-cyclobutanols with aryl bromide via $\mathrm{C}-\mathrm{C}$ bond cleavage: new approach for the $\gamma$-arylated ketones. J. Am. Chem. Soc. 121, 11010 (1999).

44. Zhang, E., Fan, C.-A., Tu, Y.-Q., Zhang, F.-M. \& Song, Y.-L. Organocatalytic asymmetric vinylogous $\alpha$-ketol rearrangement: enantioselective construction of chiral all-carbon quaternary stereocenters in spirocyclic diketones via semipinacol-type 1,2-carbon migration. J. Am. Chem. Soc. 131, 14626 (2009).

45. Song, Z.-L., Fan, C.-A. \& Tu, Y.-Q. Semipinacol rearrangement in natural product synthesis. Chem. Rev. 111, 7523 (2011).

46. Trost, B. M. \& Yasukata, T. A catalytic asymmetric Wagner-Meerwein shift. J. Am. Chem. Soc. 123, 7162 (2001).

47. Seiser, T. \& Cramer, N. Enantioselective C-C bond activation of allenyl cyclobutanes: access to cyclohexenones with quaternary stereogenic centers. Angew. Chem. Int. Ed. 47, 9294 (2008).

48. Sohn, S. S. \& Bode, J. W. Catalytic generation of activated carboxylates from enals: a product-determining role for the base. Org. Lett. 7, 3873 (2005).

49. Kerr, M. S., Read de Alaniz, J. \& Rovis, T. An efficient synthesis of achiral and chiral 1,2,4-triazolium salts: bench stable precursors for $N$-heterocyclic carbenes. J. Org. Chem. 70, 5725 (2005).

50. He, M., Struble, J. R. \& Bode, J. W. Highly enantioselective azadiene Diels-Alder reactions catalyzed by chiral $N$-heterocyclic carbenes. J. Am. Chem. Soc. 128, 8418 (2006).

51. Vora, H. U. \& Rovis, T. Nucleophilic carbene and HOAt relay catalysis in an amide bond coupling: an orthogonal peptide bond forming reaction. J. Am. Chem. Soc. 129, 13796 (2007).

52. Vora, H. U., Moncecchi, J. R., Epstein, O. \& Rovis, T. Nucleophilic carbene catalyzed synthesis of 1,2-amino alcohols via azidation of epoxy aldehydes. J. Org. Chem. 73, 9727 (2008).

53. Zhang, M. et al. DFT study on the reaction mechanisms and stereoselectivities of NHC-catalyzed [2+2] cycloaddition between arylalkylketenes and electrondeficient benzaldehydes. Org. Biomol. Chem. 12, 6374 (2014).

54. Davies, A. T., Pickett, P. M., Slawin, A. M. Z. \& Smith, A. D. Asymmetric synthesis of tri- and tetrasubstituted trifluoromethyl dihydropyranones from $\alpha$-aroyloxyaldehydes via NHC redox catalysis. ACS Catal. 4, 2696 (2014).

55. Douglas, J., Taylor, J. E., Churchill, G., Slawin, A. M. Z. \& Smith, A. D. NHC-Promoted asymmetric $\beta$-lactone formation from arylalkylketenes and electron-deficient benzaldehydes or pyridinecarboxaldehydes. J. Org. Chem. 78, 3925 (2013).

56. Um, J. M., DiRocco, D. A., Noey, E. L., Rovis, T. \& Houk, K. N. Quantum mechanical investigation of the effect of catalyst fluorination in the intermolecular asymmetric stetter reaction. J. Am. Chem. Soc. 133, 11249 (2011).

57. Danheiser, R. L., Carini, D. J. \& Basak, A. Trimethylsilyl)cyclopentene annulation: a regiocontrolled approach to the synthesis of five-membered rings. J. Am. Chem. Soc. 103, 1604 (1981).

58. Enders, D. \& Balensiefer, T. Nucleophilic carbenes in asymmetric organocatalysis. Acc. Chem. Res. 37, 534 (2004).

59. Nair, V., Vellalath, S. \& Babu, B. P. Recent advances in carbon-carbon bond-forming reactions involving homoenolates generated by NHC catalysis. Chem. Soc. Rev. 37, 2691 (2008).

60. Biju, A. T., Kuhl, N. \& Glorius, F. Extending NHC-catalysis: coupling aldehydes with unconventional reaction partners. Acc. Chem. Res. 44, 1182 (2011).

61. Cohen, D. T. \& Scheidt, K. A. Cooperative Lewis acid/N-heterocyclic carbene catalysis. Chem. Sci 3, 53 (2012).

62. Grossmann, A. \& Enders, D. N-heterocyclic carbene catalyzed domino reactions. Angew. Chem. Int. Ed. 51, 314 (2012).

63. Izquierdo, J., Hutson, G. E., Cohen, D. T. \& Scheidt, K. A. A continuum of progress: applications of $\mathrm{N}$-hetereocyclic carbene catalysis in total synthesis. Angew. Chem. Int. Ed. 51, 11686 (2012).

64. Sarkar, S. D., Biswas, A., Samanta, R. C. \& Studer, A. Catalysis with $N$-heterocyclic carbenes under oxidative conditions. Chem. Eur. J 19, 4664 (2013).

65. Ryan, S. J., Candish, L. \& Lupton, D. W. Acyl anion free $N$-heterocyclic carbene organocatalysis. Chem. Soc. Rev. 42, 4906 (2013).

66. Hopkinson, M. N., Richter, C., Schedler, M. \& Glorius, F. An overview of $N$-heterocyclic carbenes. Nature 510, 485 (2014).

67. Chauhan, P. \& Enders, D. N-heterocyclic carbene catalyzed activation of esters: a new option for asymmetric domino reactions. Angew. Chem. Int. Ed. 53, 1485 (2014).

\section{Acknowledgements}

Generous financial supports for this work are provided by: Singapore National Research Foundation, Singapore Economic Development Board (EDB), GlaxoSmithKline (GSK) and Nanyang Technological University (NTU), China's National Key program for Basic Research (No. 2010CB 126105), Thousand Talent Plan, the National Natural Science Foundation of China (No. 21132003, No. 21472028) and Guizhou University (China).

\section{Author contributions}

B.-S.L. conducted most of the experiments; Y.W., Z.J. and P.Z. prepared the substrates and catalysts for the reaction scope evaluation; R.G. contributed to X-ray analysis. Y.R.C. conceptualized and directed the project, and drafted the manuscript with the assistance from all the co-authors. All authors contributed to discussions.

\section{Additional information}

Accession codes: For ORTEPs of products $\mathbf{3 b}, \mathbf{3 m}, \mathbf{5 f}$ and $\mathbf{5 g}$, see Supplementary Information. CCDC 988901, CCDC 988902, CCDC 1011138 and CCDC 1011137 contain supplementary crystallographic data for this paper. These data could be obtained free of charge from The Cambridge Crystallographic Data Centre via www.ccdc.cam. ac.uk/data_request/cif.

Supplementary Information accompanies this paper at http://www.nature.com/ naturecommunications

Competing financial interests: The authors declare no competing financial interests.

Reprints and permission information is available at http://npg.nature.com/ reprintsandpermissions/

How to cite this article: Li, B.-S. et al. Carbon-carbon bond activation of cyclobutenones enabled by the addition of chiral organocatalyst to ketone. Nat. Commun. 6:6207 doi: 10.1038/ncomms7207 (2015).

This work is licensed under a Creative Commons Attribution 4.0 International License. The images or other third party material in this article are included in the article's Creative Commons license, unless indicated otherwise in the credit line; if the material is not included under the Creative Commons license, users will need to obtain permission from the license holder to reproduce the material. To view a copy of this license, visit http://creativecommons.org/licenses/by/4.0/ 